\title{
Lost in translation? Bridging the preclinical / clinical divide
}

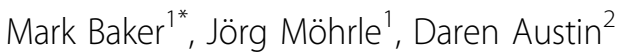 \\ From Challenges in malaria research \\ Basel, Switzerland. 10-12 October 2012
}

Establishing the relevance of preclinical data to the clinical situation is a problem that has plagued drug development in the majority of therapeutic areas. Typically a drug development cascade relies on preclinical data assuming the in vitro and in vivo data are consistent and predict some elements of clinical efficacy. Quantitative translation from preclinical to clinical is model based and requires PK (pharmacokinetics) and PK/PD (pharmacokinetic/pharmacodynamics) models linking drug exposure with effect.

The first modeling step undertaken for anti-malaria drug development at MMV has been to develop a model capable of linking preclinical in vitro to preclinical in vivo data to:

- Derive efficacy parameters for scaling including additional parameters that put them in context (parasite growth rates and maximum rates of killing)

- Determine the relationship and consistency between the in vitro and preclinical in vivo data.

This approach, whilst using data from a broader range of compounds and mechanisms, does assume that preclinical data is relevant replicating, at least partially, the clinical disease.

The in vitro data characterized the effects of fixed concentrations of compound on the reduction of $P$ falciparum parasite concentrations and estimated IC50s. The in vivo assessment in SCID mice determined the compound's dose-dependent reduction of $P$ falciparum parasite concentrations and estimated an ID90. The in vivo data was modelled using a nonlinear mixed effects PK/PD model in Nonmem and its parameter estimates compared to those from the in vitro data.

The modeling was performed in a step-wise approach where a PK model was fitted to concentration time

${ }^{1}$ Translational Medicine, Medicines for Malaria Venture, 1215 Geneva 15,

Switzerland

Full list of author information is available at the end of the article course data from a single dose in order to simulate the time courses used in the efficacy study (4 doses, 24 hours apart). The PK/PD model was then fitted to the observed parasitemia data using the simulated concentrations. The PD model estimated baseline parasitemia, rate constants for parasite growth and death, and the concentration dependent moderation of parasite death. The model determined that the parasite concentration expanded by approximately 3-4 times every 48 hours (in contrast to approximately 10 times in humans). For the two compounds modeled to date, model-estimated IC50 values from the in vivo data matched the in vitro estimates of IC50. The model, using the estimated parameters was also able to accurately simulate the decline in parasitemia and subsequent recrudescence following a single dose in the SCID P falciparum model providing some mechanistic validation.

This modeling is at an early phase requiring more data, preclinical and clinical, for validation including evaluating methods for the prediction of clinical PK. The agreement between in vivo and in vitro parameter estimates is encouraging and will be confirmed as Agreement between in vitro and in vivo parameters is encouraging as is the model's ability to capture parasitemia dynamics. A simple approximation of this model is being evaluated for use in assessing MMV's preclinical candidates. In addition to confirming the model's preclinical utility, clinical data is being sought to test whether the model is equally able in predicting drug effects on $P$ falciparum in humans, confirming the relevance of preclinical data.

\section{Acknowledgements}

The Translational Medicine and Discovery departments, MMV. Diseases of the Developing World Biology and DMPK departments, GlaxoSmithKline, Tres Cantos.
C Biomed Central

C 2012 Baker et al; licensee BioMed Central Ltd. This is an Open Access article distributed under the terms of the Creative Commons Attribution License (http://creativecommons.org/licenses/by/2.0), which permits unrestricted use, distribution, and reproduction in any medium, provided the original work is properly cited. 


\section{Author details}

'Translational Medicine, Medicines for Malaria Venture, 1215 Geneva 15,

Switzerland. ${ }^{2}$ Quantitative Sciences, GlaxoSmithKline, Stockley Park, UK.

Published: 15 October 2012

doi:10.1186/1475-2875-11-S1-P112

Cite this article as: Baker et al:: Lost in translation? Bridging the

preclinical / clinical divide. Malaria Journal 2012 11(Suppl 1):P112.

Submit your next manuscript to BioMed Central and take full advantage of:

- Convenient online submission

- Thorough peer review

- No space constraints or color figure charges

- Immediate publication on acceptance

- Inclusion in PubMed, CAS, Scopus and Google Scholar

- Research which is freely available for redistribution

Submit your manuscript at 